\title{
Solar Cycle and Seasonal Distribution of Geomagnetic Storms with Sudden Commencement
}

\author{
Gustavo A. Mansilla ${ }^{1,2}$ \\ ${ }^{1}$ Departamento de Física, Facultad de Ciencias Exactas y Tecnología, Universidad Nacional de Tucumán, Av \\ Independencia 1800, 4000 San Miguel de Tucumán, Argentina \\ ${ }^{2}$ Consejo Nacional de Investigaciones Científicas y Técnicas, Argentina \\ Correspondence: Gustavo A. Mansilla, Departamento de Física, Facultad de Ciencias Exactas y Tecnología, \\ Universidad Nacional de Tucumán, San Miguel de Tucumán, Argentina. Tel: 54-0381-4364093. E-mail: \\ gmansilla@herrera.unt.edu.ar
}

Received: November 6, 2013 Accepted: December 6, 2013 Online Published: December 30, 2013

doi:10.5539/esr.v3n1p50 URL: http://dx.doi.org/10.5539/esr.v3n1p50

\begin{abstract}
In this brief paper the seasonal and solar cycle distribution of storms with sudden commencement is presented. A correlation between the number of geomagnetic storms by month and monthly sunspot numbers is observed. Also, a pronounced seasonal variation of the occurrence of intense geomagnetic storms and no dependence for moderate geomagnetic storms, which occur more frequently than the intense ones during the solar cycles.
\end{abstract}

Keywords: solar cycle, seasonal variation, geomagnetic storms

\section{Introduction}

It is known since several decades that the geomagnetic activity tends to be higher on average at the equinoxes than at the solstices. Only recently, has been noticed that this seasonal variation is especially prominent when large geomagnetic storms are considered (e.g., Richardson et al., 2001). However, there is currently no accepted explanation for this behavior of great storms (e.g., Tsurutani \& Gonzalez, 1995).

In analogy with weather storms on Earth's surface, significant perturbations of the geomagnetic field from normal behavior are produced, which have been called geomagnetic storms. Geomagnetic storms represent the single most important space weather phenomenon and also are an exciting and rewarding topic that covers an interesting spectrum of ionosphere-magnetosphere interactions (Singh et al., 2010).

Geomagnetic storms are caused mainly by solar wind transients from the coronal mass ejections (CMEs) and solar flares or by the corotating interaction regions (CIRs) formed during the interaction between the high and low speed streams (Rawat et al., 2009). Occurrence frequency and intensity of transient solar emissions vary with different phases of the solar cycle characterized by the number of sunspots on the photosphere. Solar maximum is dominated by powerful solar eruptions, like solar flares and CMEs. On the other hand, the solar minimum is featured by coronal holes and fast wind streams (Tsurutani \& Gonzalez, 1998).

Most dominant mechanism for transfer of solar wind energy into the magnetosphere to produce the geomagnetic storms is magnetic reconnection between southwardly oriented IMF $\mathrm{Bz}$ component and the antiparallel geomagnetic field lines (see e.g., Rawat et al., 2009 and references therein).

These geomagnetic storms in the Earth's magnetosphere and ionosphere subsequently intense auroral activity, satellite damage, transformer failures and tripping of power grids (Alex et al., 2006).

The classical geomagnetic storms consist of three phases:

1) An increase of the Earth's magnetic field lasting a few hours (initial phase);

2) A pronounced decrease in the horizontal component $\mathrm{H}$, reaching a maximum (negative) in about one day (main phase);

3) A slow recovery in $\mathrm{H}$, reaching normal values over several days (recovery phase).

It is known that the initial phase is caused by the compression of the magnetosphere by the arrival of an intensified solar plasma, often related to solar flares. The decrease in intensity is due to an enhancement of 
charged particles in the ring current. This enhanced ring current, principally formed by protons, oxygen ions and electrons drifting to the west and to the east respectively, produces a magnetic field disturbance which at the equator is opposite to the Earth's dipole field. The recovery phase of the storm is due to the decay of energetic particles of the ring current (namely removal of trapped ions in charge-exchanging collisions with neutral atoms).

Values of the average global variation of the low-latitude H component are represented by the Dst index, which is considered as a good measure of the intensity of the ring current being the strength of the geomagnetic storms measured usually by the magnitude of the Dst index.

Based on the experimental and analytical evidence of $\mathrm{O}^{+}$injection into the ring current, it was concluded that the larger the storm is (as quantified by the Dst index) the larger the $\mathrm{O}^{+}$contribution to the ring current; the Dst magnitude and the $\mathrm{O}^{+}$contribution to the ring current increase at same time (Singh et al., 2010).

The range of observed Dst values is approximately from $+100 \mathrm{nT}$ to $-600 \mathrm{nT}$. Intense storms are those with peak Dst of $-100 \mathrm{nT}$ or less, moderate storms with peak Dst between $-50 \mathrm{nT}$ and $-100 \mathrm{nT}$, and weak storms with peak Dst between $-30 \mathrm{nT}$ and $-50 \mathrm{nT}$ (Sugiura \& Chapman, 1960).

In the case of intense magnetic storms the major interplanetary drivers are CMEs (Echer et al., 2006; Gonzalez et al., 2007).

The majority of storms begin with a sudden impulse which signals the arrival of solar plasma. During this time, the geomagnetic field intensity is increased, the storm-time H component being positive. Such sudden impulses preceding geomagnetic storms are called storm sudden commencements.

There is another type of geomagnetic storms in which its onset time is not very evident, so that they are called gradually commencing storms. This less frequent type of storms are not considered in this paper.

The aim of this brief paper is to present the solar cycle and seasonal distribution of geomagnetic storms with sudden commencement (SC) and the principal mechanisms proposed to account the seasonal variation of geomagnetic storms. The period considered is from 1953 to 2008 (solar cycles 19, 20, 21, 22 and 23). The solar cycle activity is represented by sunspot numbers, obtained of Solar-Geophysical Data prompt reports.

\section{Results and Discussion}

The storm sudden commencements by date were provided by the World Data Center for Solar-Terrestrial Physics, Moscow (www.wdcb.ru/stp/index-en.html) and the peak Dst were obtained from the hourly Dst values provided by the World Data Center for Geomagnetism, Kyoto (wdc.kugi.kyoto-u.ac.jp/wdc/Sec3.html).

Figure 1 shows an example of the temporal variation of the Dst index during an intense geomagnetic storm occurred on 24 August 2005, in which can be seen the different phases of the storm. The sudden commencement (SC) of the storm was at 0613 UT on August 24. The main phase remained till about 12 UT reaching a minimum value of $-216 \mathrm{nT}$ after which begin a slow recovery phase.

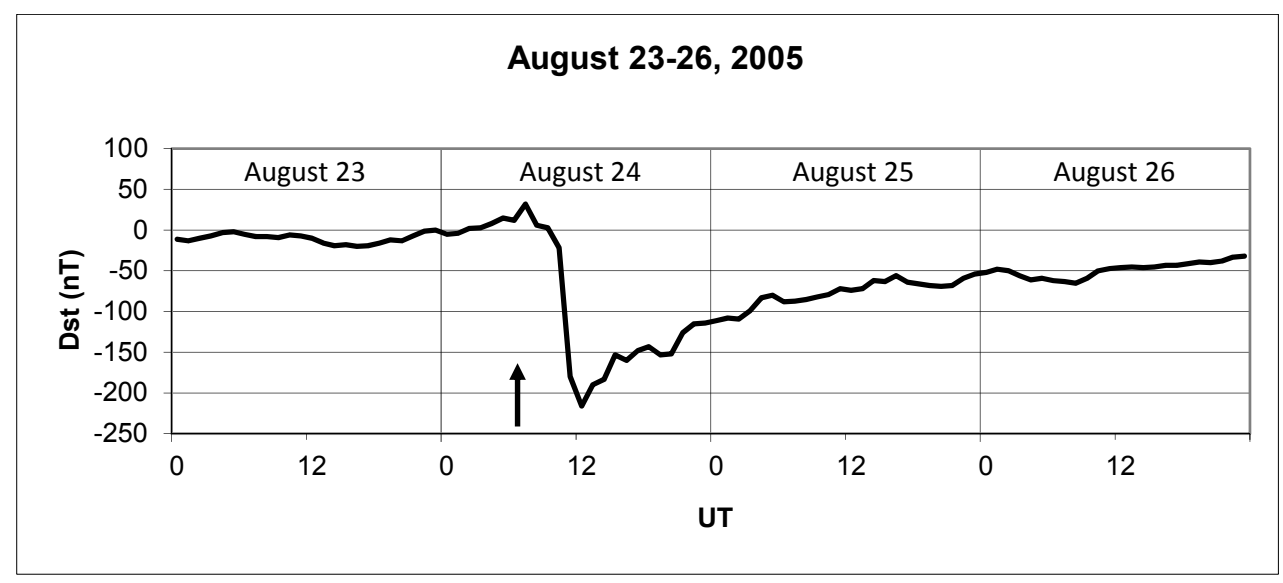

Figure 1. Example of the hourly variation of the Dst index for the storm period 23-26 August 2005. The arrow indicates the storm sudden commencement (SC) at 0613 UT on August 24

We have identified all the storms of the period 1953-2008 by examining the more negative Dst hourly value 
reached during each storm period. In this way was determined the intensity for each geomagnetic storm. Also, it was counted the total number of storms occurred in each month (weak, moderate and intense).

Thus, Figure 2 shows the number of storms with sudden commencement by month $\mathrm{N}$ and the mean monthly sunspot numbers from 1953 to 2008 (red line). It can be seen that the number of storms by month varies in correlation with sunspot numbers: the maxima $\mathrm{N}$ values are produced near the solar maximum and the minimal $\mathrm{N}$ values around the solar minimum. It is noticed that the great values of $\mathrm{N}$ occurred during the descending phase of the solar cycle.

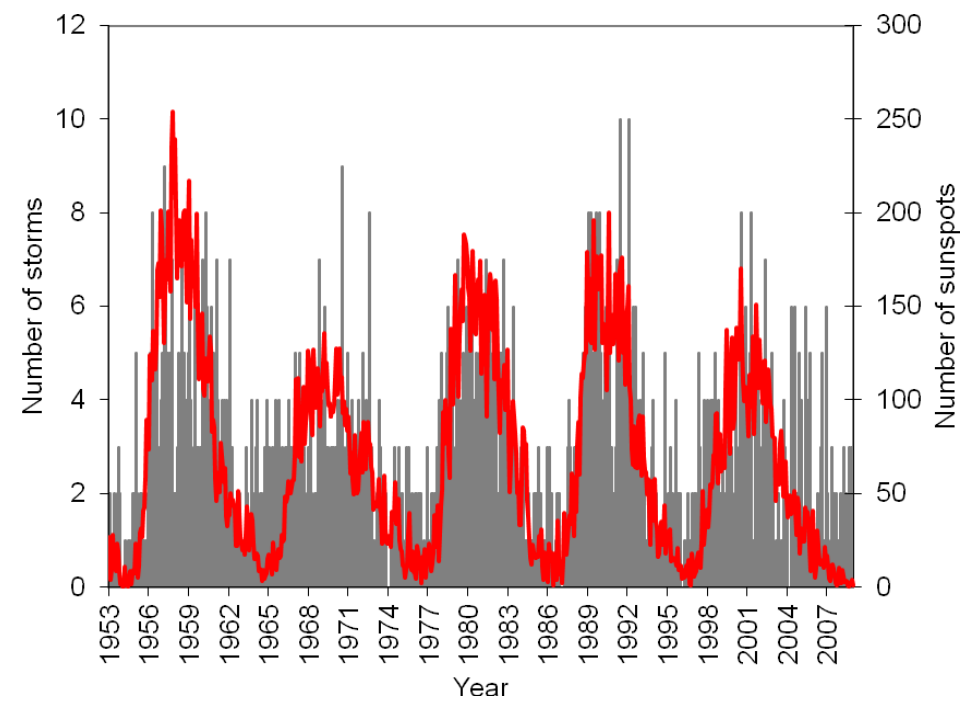

Figure 2. Number of storms by month and monthly sunspot numbers (red line) for the interval 1953-2008

The solar wind velocity probably contributes to enhanced storm activity observed near the solar maximum since it was found that the annual averages of the solar wind velocity (and also the solar wind plasma temperature) exhibits 11-year periodic variations (Nakai \& Kamide, 1994).

The seasonal variation of intense storms $\mathrm{R}$ we computed as follows:

$$
\mathrm{R}=\left(\mathrm{N}_{1} / \mathrm{N}_{2}\right) * 100
$$

Where $\mathrm{N}_{1}$ is the amount of the intense storms occurred in all the January, February, etc. of the solar cycle and $\mathrm{N}_{2}$ is the total number of intense storms occurred during the corresponding solar cycle.

Figure 3 shows the seasonal distribution of intense storms (peak Dst $<-100 \mathrm{nT}$ ), in percentage, that occurred within four solar cycles: 20 (1965-1975), 21 (1976-1986) y 22 (1987-1997) and 23 (1998-2008). In general, it can be seen in this figure a seasonal variability, with maxima around the months March, April and May and from August to November (around equinoxes) and minimum around the solstices (June, July). A prominent feature exhibited the seasonal variation during solar cycle 23: two peaks can be noted in August and November. Also, the occurrence frequency of the intense geomagnetic storms is larger from March to May than in August-November, except for solar cycle 23 where the reverse occurred.

Analyzing superintense storms (Dst index $\leq-250 \mathrm{nT}$ ), Gonzalez et al. (2011) found similar results to obtained here, namely that they have a dual-type distribution in the solar cycle, one at solar maximum and the second at the descending phase of the cycle, and a seasonal distribution showing the equinoctial peaks and an additional peak in July.

Three principal mechanisms have been proposed to account for the seasonal variation of geomagnetic activity: 1the "axial" hypothesis (Cortie, 1912), invoking driving forces varying with the heliographic latitude of the Earth; 2- the "equinoctial" hypothesis (Bartels, 1932; Svalgaard, 1977) based in that activity is modulated by a process sensitive to the angle between the geomagnetic dipole end the direction to the Sun; and the "Russell-McPherron" hypothesis (Russell \& McPherron, 1973), leading to enhanced southward heliospheric magnetic field, and hence enhanced reconnection.

Some authors (e. g., Temerin \& Li, 2002; O’Brien \& Mc Pherron, 2002; Svalgaard et al., 2002) consider that 
equinoctial hypothesis plays the more important role to cause the seasonal variation because their results are consistent with the equinoctial hypothesis and inconsistent with either a dominant axial or Russell-McPerron effect.

Dst<-100 nT

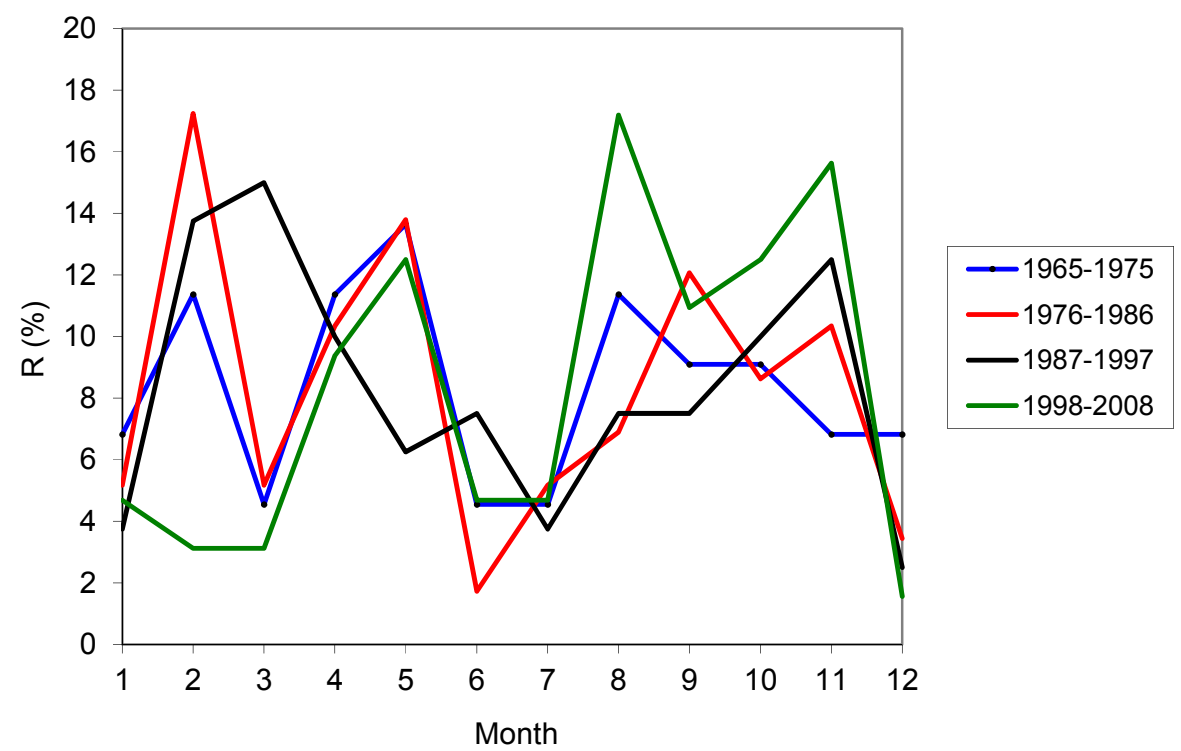

Figure 3. Seasonal variation of intense geomagnetic storms for the periods 1965-1975, 1976-1986, 1987-1997 and 1998-2008

The semiannual variation in geomagnetic activity is well established in geomagnetic data and it is generally attributed to the Russell-McPherron effect. In that picture, enhancements of southward field $B_{s}$, near the equinoxes account for the observed higher geomagnetic activity in March-April and from August to November, that is, there is a semiannual variation in the effective southward component of the interplanetary magnetic field.

There is other less accepted mechanism to explain the seasonal dependence of geomagnetic activity, which is related with the lack of "Solar Illumination" of one polar ionosphere at each solstice, reducing geomagnetic activity (Patowary et al., 2013).

While all of these mechanisms contribute to the semiannual variation, their relative contributions have long been a matter of debate. Possibly more than one mechanism is operative at the same time with different degree of importance to produce the seasonal dependence.

Figure 4 is the same that Figure 3, but for moderate geomagnetic storms (peak Dst between $-50 \mathrm{nT}$ and $-100 \mathrm{nT}$ ). Notice that in general in these storms is not observed the seasonal modulation found for intense storms (except for solar cycle 23). The fluctuating distribution suggests no dependence with solar/magnetic activity.

The main interplanetary feature associated with intense storms is the presence of a large-amplitude $(<-10 \mathrm{nT})$, long-duration ( $>3$ hours), negative $\mathrm{B}_{\mathrm{z}}$ component of the interplanetary magnetic field (Gonzalez et al., 1989). These southward fields maximize at the spring (fall) equinox (Crooker et al., 1992). It is reasonable to assume that moderate storms are associated with small-amplitude negative $\mathrm{B}_{\mathrm{z}}$ fields in the interplanetary medium and with less intensity of the ring current, but evidently they not present any seasonal dependence. However, this still needs to be studied. 


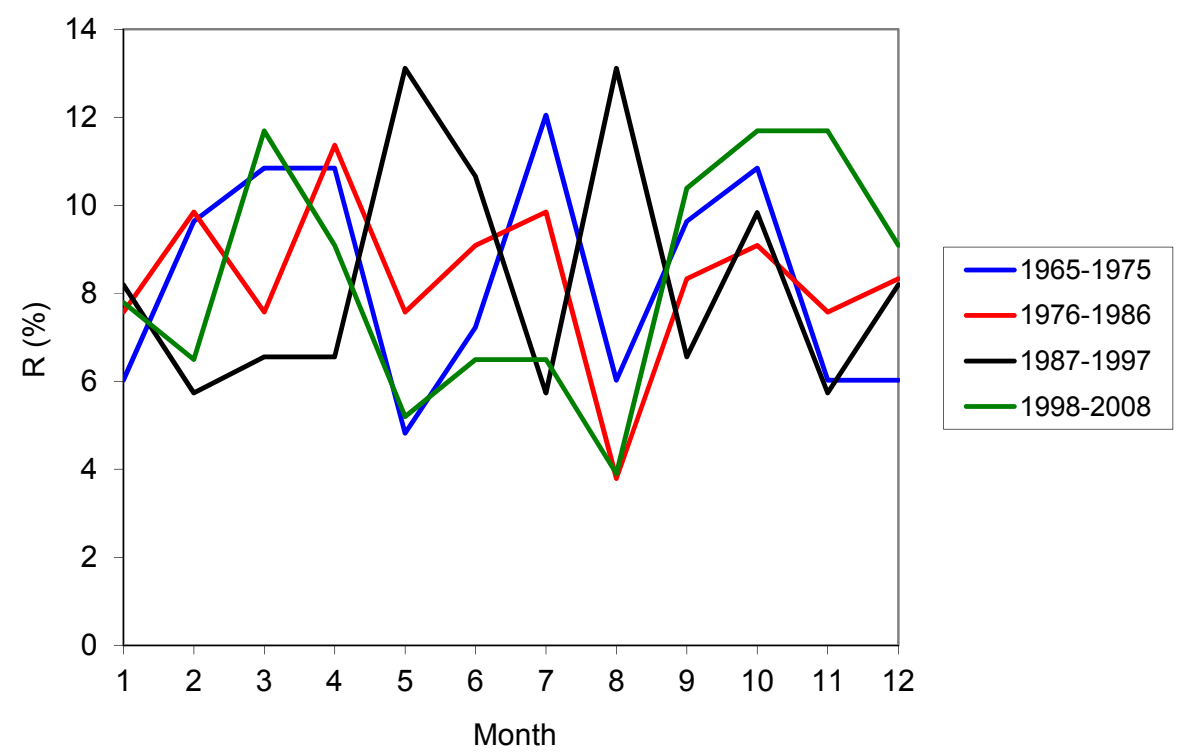

Figure 4. The same as Figure 3, but for moderate geomagnetic storms

\section{Conclusions}

In this brief paper some aspects of geomagnetic storms with sudden commencement are presented. The results obtained have clear forecasting implications, which may be summarized as follows:

(1) The greater density of storms is produced around the maximum solar cycle and during the descending phase of the solar cycle.

(2) The results suggest that there is a higher probability of producing an intense geomagnetic storm at the equinoxes than at the solstices.

(3) The occurrence frequency of intense storms is smaller than moderate storms in the solar cycles.

\section{References}

Alex, S., Mukherjee, S., \& Lakhina, G. S. (2006). Geomagnetic signatures during the intense geomagnetic storms of 29 October and 20 November 2003. Journal of Atmospheric and Solar-Terrestrial Physics, 68, 769. http://dx.doi.org/10.1016/j.jastp.2006.01.003

Bartels, J. (1932). Terrestrial-magnetic activity and its relations to solar phenomena. Terrestrial Magnetism and Atmospheric Electricity, 37(1), 1-52. http://dx.doi.org/10.1029/TE037i001p00001

Cortie, A. L. (1912). Sun-spots and terrestrial magnetic phenomena, 1898-1911. Monthly Notices of the Royal Astronomical Society, 73, 52.

Crooker, N. U., Cliver, E. W., \& Tsurutani, B. T. (1992). The semiannual variation of great geomagnetic storms and the postshock Russell - McPherron effect preceding coronal mass ejecta. Geophysical research letters, 19(5), 429-432. http://dx.doi.org/10.1029/92GL00377

Echer, E., Gonzalez, W. D., \& Alves, M. V. (2006). On the geomagnetic effects of solar wind interplanetary magnetic structures. Space Weather, 4(6), S06001. http://dx.doi.org/10.1029/2005SW000200

Gonzalez, W. D., Echer, E., Clúa de Gonzalez, A. L., Tsurutani, B. T., \& Lakhina, G. S. (2011). Extreme geomagnetic storms, recent Gleissberg cycles and space era-superintense storms. Journal of Atmospheric and Solar-Terrestrial Physics, 73(11), 1447-1453. http://dx.doi.org/10.1016/j.jastp.2010.07.023

Gonzalez, W. D., Echer, E., Clua - Gonzalez, A. L., \& Tsurutani, B. T. (2007). Interplanetary origin of intense geomagnetic storms (Dst< $-100 \mathrm{nT}$ ) during solar cycle 23. Geophysical research letters, 34(6). http://dx.doi.org/10.1029/2006GL028879

Gonzalez, W. D., Tsurutani, B. T., Gonzalez, A. L. C., Smith, E. J., Tang, F., \& Akasofu, S. J. (1989). Solar wnd-magnetosphere coupling during intense magnetic storms (1978-1979). Journal of Geophysical 
Research, 94, 8835. http://dx.doi.org/10.1029/JA094iA07p08835

Nakai, H., \& Kamide, Y. (1994). Estimating the long - term variations of the magnetotail pressure. Journal of Geophysical Research: Space Physics (1978-2012), 99(A12), 23747-23751. http://dx.doi.org/10.1029/94JA02220

O'Brien, T. P., \& McPherron, R. L. (2002). Seasonal and diurnal variation of Dst dynamics. Journal of geophysical research, 107(A11), 1341. http://dx.doi.org/10.1029/2002JA009435

Patowary, R., Singh, S. B., \& Bhuyan, K. (2013). A study of seasonal variation of geomagnetic activity. Research Journal of Physical and Applied Sciences, 2(1), 001.

Rawat, R., Alex, S., \& Lakhina, G. S. (2009). Low-latitude geomagnetic response to the interplanetary conditions during very intense magnetic storms. Advances in Space Research, 43(10), 1575-1587. http://dx.doi.org/10.1016/j.asr.2009.01.025

Richardson, I. G., Cliver, E. W., \& Cane, H. V. (2001). Sources of geomagnetic storms for solar minimum and maximum conditions during 1972-2000. Geophysical Research Letters, 28(13), 2569-2572. http://dx.doi.org/10.1029/2001GL013052

Russell, C. T., \& McPherron, R. L. (1973). Semiannual variation of geomagnetic activity. Journal of geophysical research, 78(1), 92-108. http://dx.doi.org/10.1029/JA078i001p00092

Singh, A. K., Siingh, D., \& Singh, R. P. (2010). Space weather: physics, effects and predictability. Surveys in geophysics, 31(6), 581-638. http://dx.doi.org/10.1007/s10712-010-9103-1

Sugiura, M., \& Chapman, S. (1960). The average morphology of geomagnetic storms with sudden comencement, Abandl. Akad. Wiss., Gottingen Math. Phys., K1(4).

Svalgaard, L. (1977). Geomagnetic activity: Dependence on solar wind parameters. In J. B. Zirker (Ed.), Coronal Holes and Hight Speed Streams, Colorado Associated University Press, Boulder, CO.

Svalgaard, L., Cliver, E. W., \& Ling, A. G. (2002). The semiannual variation of great geomagnetic storms. Geophysical research letters, 29(16), 12-1. http://dx.doi.org/10.1029/2001GL014145

Temerin, M., \& Li, X. (2002). A new model for the prediction of Dst on the basis of the solar wind. Journal of Geophysical Research: Space Physics (1978-2012), 107(A12), SMP-31.

Tsurutani, B. T., \& Gonzalez, W. D. (1995). The future of geomagnetic storm predictions: Implications from recent solar and interplanetary observations. Journal of Atmospheric and Terrestrial Physics, 57(12), 1369-1384. http://dx.doi.org/10.1016/0021-9169(95)00138-R

Tsurutani, B. T., \& Gonzalez, W. D. (1998). The interplanetary causes of magnetic storms: a review. In B. T. Tsurutani, W. D. Gonzalez, \& Y. Kamide (Eds.), Magnetic Storms. AGU Monograph, Washington, DC.

\section{Copyrights}

Copyright for this article is retained by the author(s), with first publication rights granted to the journal.

This is an open-access article distributed under the terms and conditions of the Creative Commons Attribution license (http://creativecommons.org/licenses/by/3.0/). 